University of Nebraska - Lincoln

DigitalCommons@University of Nebraska - Lincoln

1984

\title{
Monitoring Velocity Variations in the Crust Using Earthquake Doublets: An Application to the Calaveras Fault, California
}

G. Poupinet

Universite Scientifique et Medicale de Grenoble

W. L. Ellsworth

U.S. Geological Survey

J. Frechet

Universite Scientifique et Medicale de Grenoble

Follow this and additional works at: https://digitalcommons.unl.edu/usgsstaffpub

Part of the Earth Sciences Commons

Poupinet, G.; Ellsworth, W. L.; and Frechet, J., "Monitoring Velocity Variations in the Crust Using Earthquake Doublets: An Application to the Calaveras Fault, California" (1984). USGS Staff -- Published Research. 386.

https://digitalcommons.unl.edu/usgsstaffpub/386

This Article is brought to you for free and open access by the US Geological Survey at DigitalCommons@University of Nebraska - Lincoln. It has been accepted for inclusion in USGS Staff -- Published Research by an authorized administrator of DigitalCommons@University of Nebraska - Lincoln. 


\title{
Monitoring Velocity Variations in the Crust Using Earthquake Doublets: An Application to the Calaveras Fault, California
}

\author{
G. POUPINET
}

IRIGM, Universite Scientifique et Medicale de Grenoble, St. Martin dHeres, France

\author{
W. L. ELLSWORTH
}

U.S. Geological Survey, Menlo Park, California

\section{J. FRECHET}

IRIGM, Universite Scientifique et Medicale de Grenoble, St. Martin d'Heres, France

\begin{abstract}
We present a technique that greatly improves the precision in measuring temporal variations of crustal velocities using an earthquake doublet, or pair of microearthquakes that have nearly identical waveforms and the same hypocenter and magnitude but occur on different dates. We compute differences in arrival times between seismograms recorded at the same station in the freqency domain by cross correlation of short windows of signal. A moving-window analysis of the entire seismograms, including the coda, gives $\delta(t)$, the difference in arrival times versus running time along the seismogram. The time resolution of the method is an order of magnitude better than the digitization interval. The $\delta(t)$ technique is illustrated with a pair of microearthquakes, $M=1.7$ and 2.0 , that occurred before and after the Coyote Lake, California, earthquake ( $M=5.9$ ) of August 6, 1979, and on the same segment of the Calaveras fault that ruptured during the earthquake. The coda wave arrivals for some stations are progressively delayed for the second earthquake in the doublet, so that its seismogram appears as a stretched version of the earlier event. We interpret this systematic variation in $\delta(t)$ along the coda as a change in the average $S$ velocity in the upper crust in the time interval between the two doublets. $S$ wave velocities appear to have decreased by $0.2 \%$ in an oblong region $5-10 \mathrm{~km}$ in radius at the south end of the aftershock zone.
\end{abstract}

\section{INTRODUCTION}

The possibility that earthquakes can be accurately forecast directly from the measurement of variations in wave velocity [Semenov, 1969; Nur, 1972] stimulated considerable interest and work on the problem of making accurate, repeatable measurements of travel times in the crust. Early measurements of $V p / V s$ ratios suggested velocity changes of up to $5 \%$ preceding $M=4$ earthquakes (see Lukk and Nersesov [1978] and Rikitake [1976] for a review). However, recent studies, particularly on the San Andreas fault, have demonstrated that if any change precedes strike-slip earthquakes, it is much smaller than 1\% [Boore et al., 1975; Kanamori and Fuis, 1976; Wesson et al., 1977]. Up to now, the highest precision achieved in monitoring temporal variations of velocities have come from experiments utilizing repeatable sources such as explosions, air guns, or mechanical vibrators [Reasenberg and Aki, 1974; Buchbinder and Keith, 1979; Leary et al., 1979; Clymer and McEvilly, 1981]. For example, Leary and Malin [1982] report a precision of 1-2 ms (milliseconds) for first arrivals recorded at $10-$ to $20-\mathrm{km}$ distances and $3-5 \mathrm{~ms}$ for secondary arrivals.

In this paper we will show that a microearthquake doublet (i.e., pair of similar earthquakes) is a very convenient source for seismic velocity monitoring that allows very accurate timing measurements. Since doublets are situated inside the active seismic zone, they also provide more direct sampling of

Copyright 1984 by the American Geophysical Union.

Paper number 4B0466.

0148-0227/84/004B-0466\$05.00 the seismogenic zone surface energy sources. They are also richer in shear wave energy.

We demonstrate an accuracy of about $1 \mathrm{~ms}$ in the measurement of differential travel times, which is 10-50 times better than previously achieved with natural earthquakes. In our technique for analyzing doublets we can also make use of information in the coda. Coda waves are perhaps the most sensitive to velocity variations, since they are believed to consist mainly of $S$ waves scattered along numerous paths through the crust. In a previous study [Poupinet et al., 1982], differential $\boldsymbol{P}$ wave travel times recorded by the U.S. Geological Survey (USGS) central California seismographic network (Calnet) were measured with a precision of $4 \mathrm{~ms}$, using a crosscorrelation method. A similar method of analysis was also used by Nakamura [1978] in his study of deep moonquakes.

\section{DOUBLETS}

In large collections of microearthquakes, events with very similar waveforms are observed. They seem to originate from the same location, and Geller and Mueller [1980] have postulated that they are the expression of stress release on the same part of the fault. We call such nearby earthquakes a doublet when their waveforms are nearly identical. If the seismograms of the doublet are identical, this would require not only that the source processes are identical (hypocenter and moment tensor) but also that the medium properties (velocity, aneulastic attenuation, scattering) are also invariant. To search for possible temporal variations of crustal properties, we select doublets that occur on different dates.

Here we study two events located on the section of the Calaveras fault that ruptured during the $M=5.9$ Coyote Lake earthquake of August 6, 1979 [Lee et al., 1979; Urham- 
mer, 1980; Reasenberg and Ellsworth, 1982]. The first microearthquake occurred at $1248: 30.8$ on June 15,1978 (780615), and the second on February 28, 1980, at 1231:48.30 (800228); their common hypocenter is $36^{\circ}-58.43^{\circ} \mathrm{N}, 121^{\circ}$ $27.70^{\circ} \mathrm{W}$ and $Z=3.77 \mathrm{~km}$. This location is near the southern tip of the aftershock zone of the Coyote Lake earthquake. The first shock preceded the main shock by 14 months and the second followed it by 7 months. Their magnitudes are 1.7 and 2.0 , and they were recorded by 24 seismic stations within a radius of $30 \mathrm{~km}$.

The seismograms for each event were detected by the shortperiod (1 Hz) vertical seismometers in Calnet (Figure 1) and were transmitted by telephone line to Menlo Park as frequency-modulated, multiplexed, analog signals, where they were recorded on magnetic tape [Eaton, 1977]. A critical feature of the data collection system for our purposes is the recording of up to eight channels as well as time codes on each of 14 tape tracks on a single tape which we shall use to minimize timing errors of individual traces.

\section{TeChNique of ANALysis}

Seismograms were digitized at a rate of 100 samples per second on the Eclipse computer system of the USGS in Menlo Park. Typical seismograms for doublet 780615-800228 are strikingly similar (Figure 2). To process these signals, we use a moving-window technique. A $1.2-\mathrm{s}$ window with $50 \%$ cosine taper is moved along the whole length of each seismogram and the Fourier transform of the two windowed seismograms is computed. The delay between the two signals is evaluated in the frequency domain with a cross-correlation method. First, the two traces are aligned to the nearest sample (hundredth of a second) to avoid bias in the delay estimation. For a given time window $i$ the Fourier transform $A 1_{i}(f)$ and $A 2_{i}(f)$ are computed, $f$ being the frequency. The cross spectrum $S_{i}(f)$ is defined by

$$
S_{i}(f)=A 2^{*}{ }_{i}(f) A 1_{i}(f)
$$

where the asterisk denotes the complex conjugate. The coher-

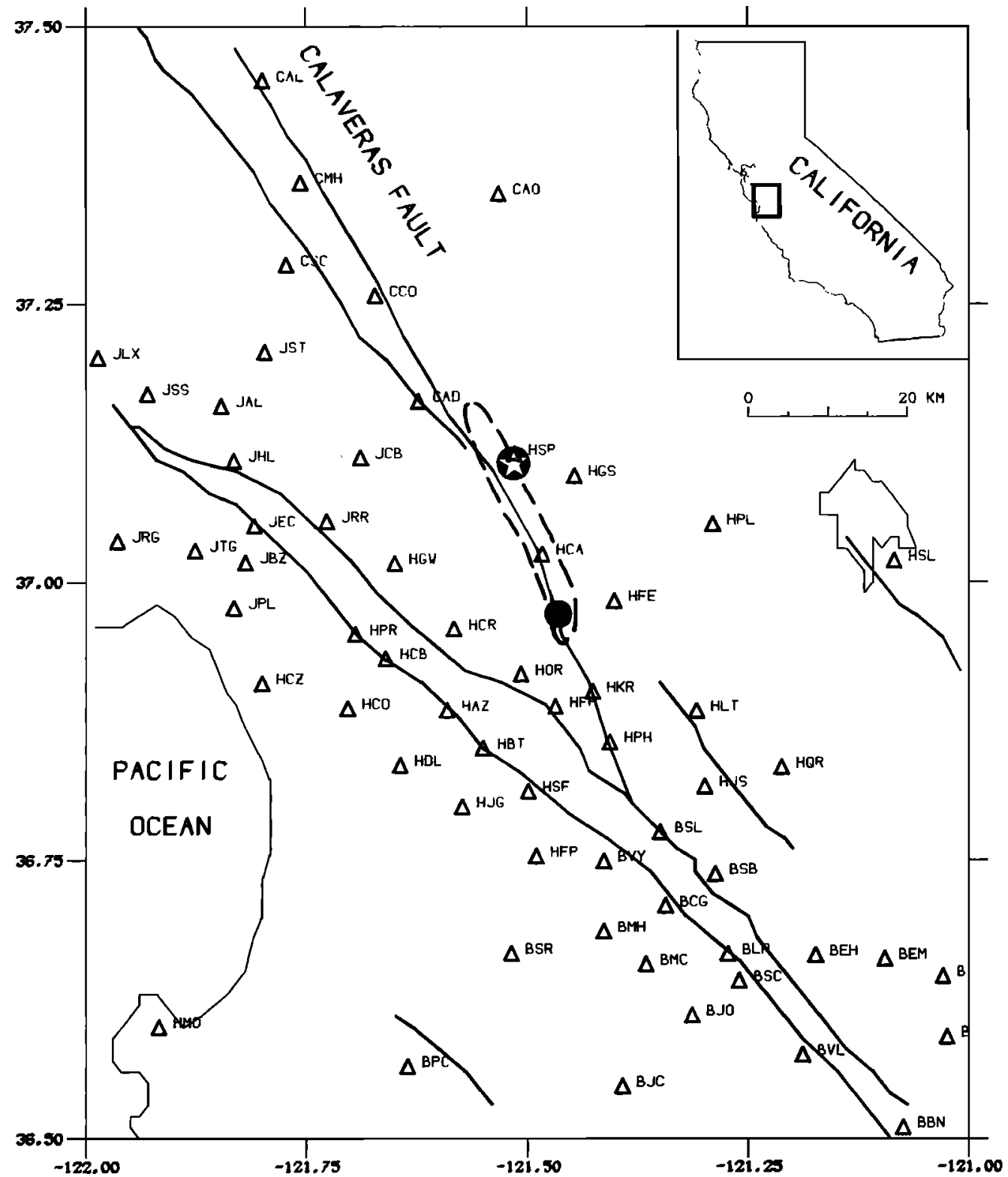

Fig. 1. Map showing the locations of the seismographic network used in this study. The Coyote Lake earthquake is indicated by a star and the doublet $780615-800228$ by a circle. The aftershock zone is outlined by the dotted line. 

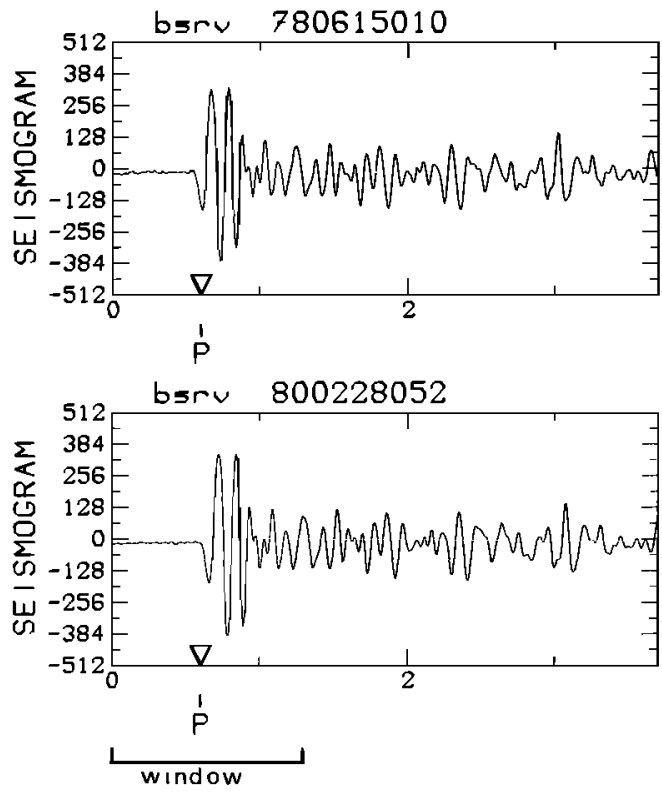

Fig. 2. Example of two seismograms recorded on 780615 and 800228 in station BSRV.

ence is calculated from smothed spectra $A 1_{i}, A 2_{i}$ and cross spectrum $S_{i}$ using a centered five-point triangular operator [Glangeaud, 1981]:

$$
C_{\mathrm{i}}(f)=\frac{S_{i}{ }^{2}(f)}{A 1_{i}(f) A 2_{i}(f)}
$$

The phase $\phi(f)$ of the cross spectrum is obtained directly from the complex valued $S_{i}(f)$ (Figure 3 ). The time delay $\delta_{i}$ between the two windowed signals is obtained by fitting a line, starting at the origin, to the phase of the cross-spectrum $\phi(f)=2 \pi \delta_{i} f$, where $\delta_{i}$ is the time delay and the phase $\phi$ is expressed in radians. In computing the time delay by least squares each phase point is weighted by a factor $C_{i}{ }^{2} /\left(1-C_{i}{ }^{2}\right)$. With this technique, we can obtain timing precision that is significantly better than the digitization rate ( $0.01 \mathrm{~s})$. Remarkably, this procedure can be successfully applied to clipped data from Calnet. Tests with clipped and unclipped versions of the same seismograms produced changes in the delay of less than $0.5 \mathrm{~ms}$. This is possible because the phase of the seismogram is not distorted by clipping in the Calnet system [Ellis and Lindh, 1976].

Before discussing the results of this analysis, we must assess the uncertainties introduced during the data acquisition process. As we compute arrival time differences, an observed change could be caused by a variation of the instrumental delays in the seismic system between the two earthquakes and not by a change in the earth. There are two different classes of possible errors. The first class consists of errors that vary along the seismogram, changing the slope of the delay curve. The second class corresponds to errors that are constant over the time span of the seismogram (about $30 \mathrm{~s}$ ) and thus modify only the absolute value of the delay. Let us investigate these two kinds of errors.

\section{Errors Varying Along the Seismogram}

We consider here only errors due to variations in tape speed and assume that no change in delay occurs along the path from the seismometer to the tape recorder within the 30-s duration of the seismogram. The frequency-modulated signals
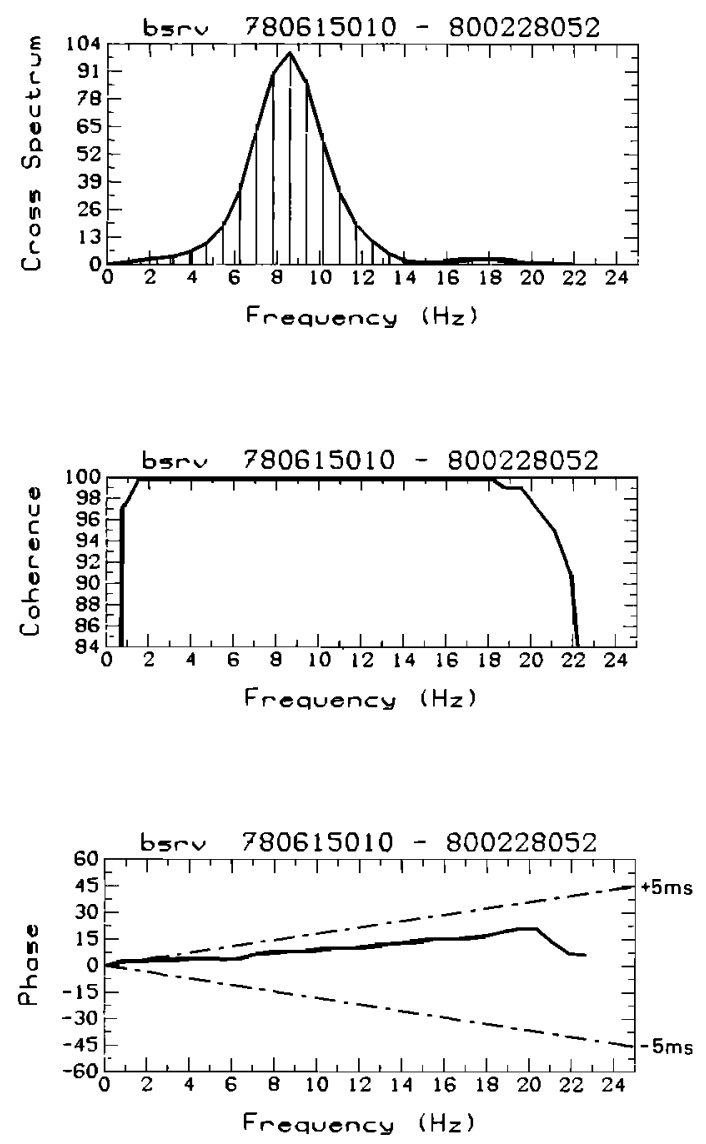

Fig. 3. Cross spectrum, coherence, and phase of the cross spectrum for the two seismograms shown in Figure 2 in the time window indicated by the bar.

are recorded continously on high-quality magnetic tapes with an accurate time code (IRIG E) and a reference sinuosid added on each track. Later, they are copied onto another tape containing all the local events. Eventually, the signal is read from the dubbed tape, demultiplexed, demodulated, and digitized. Each time a tape drive is used (4 times for one earthquake), a speed error due to capstan vibrations and long-term speed drift is added to the signal, slightly modifying the time scale.

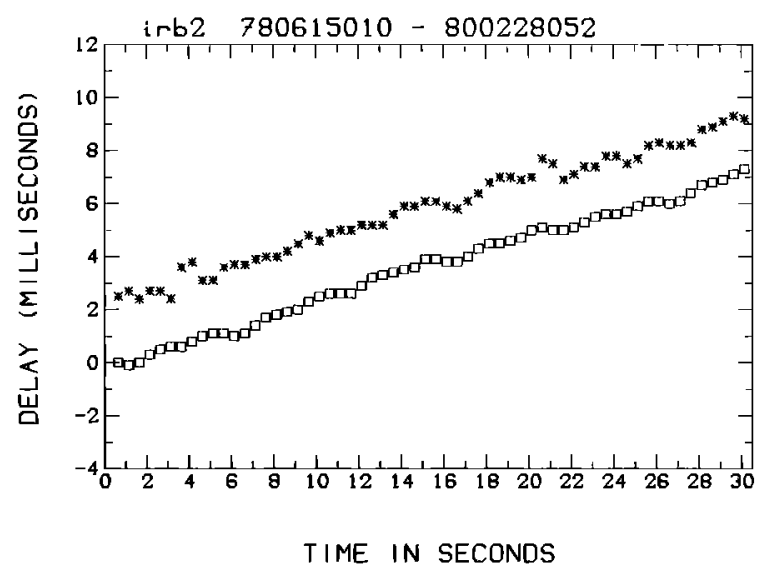

Fig. 4. Comparison of time drift computed from cross spectrum of time signals (stars) and of time drift computed from the reference sinusoid (squares). 
Fortunately, it is possible to recover all these errors by comparing the output of the time signals and of the reference sinusoid. During the digitization of each earthquake we digitize the time code and the reference sinusoid. We perform the cross-spectral analysis of the time code of both earthquakes. This time code analysis typically shows a drift of the order of $0.3 \mathrm{~ms} / \mathrm{s}$. All the delay plots (Figure 6) have been corrected for this tape speed error, using time code delays. The same computation has been independently carried out using the reference signal and the time codes (Figure 4). However, the reference signal does not give the absolute level of the time drift but only its variation.

\section{Errors Without Drift}

The response curves of the different instruments (seismometers, amplifiers, modulators) are carefully matched before installation in the field and should not vary by more than a few percent between any given pair of instruments [Healy and $O^{\prime} N$ Neill, 1977]. Such variations should not change the results significantly, but they are the most difficult source of uncertainty to eliminate. In Table 1 we identify the instrumental changes that were made between 1978 and 1980 . The digitiza- tion equipment and procedures have remained constant during all the digitization process, thus avoiding any uncertainty about this part of the data acquisition (both events were digitized on the same day). Nevertheless, some stations had to be digitized through a different analog to digital (A/D) channel as the digitizer, driven by the Eclipse computer, digitizes 32 channels (i.e., stations) at a time, the 32 channels are scanned in $0.007 \mathrm{~s}$, but are supposed by the computer to correspond to the same time. Hence if a given station is digitized through two different channels for the two earthquakes, we have to correct the delay by $0.007^{*}(\mathrm{~N} 1-\mathrm{N} 2) / 31$, where $\mathrm{N} 1$ and $\mathrm{N} 2$ are the digitization channel numbers. We call this error the digitization skew error. The linearity of this error versus channel number has been demonstrated by cross-correlating a common signal digitized through all the channels: it is constant within $0.0001 \mathrm{~s}$. After all tape speed and skew corrections have been applied, we believe that the residual time base variations are no larger than about $0.1-0.5 \mathrm{~ms}$.

Finally, we have to check for a possible change of telephone line delay. This change would be common for all eight stations that are multiplexed on the same line and should be easy to observed in $\boldsymbol{P}$ wave arrival time differences for the complete station set. However, the small scatter in $P$ delay (see below)

TABLE 1. The $\delta(t)$ Analysis Results for Doublet 780615-800223

\begin{tabular}{|c|c|c|c|c|c|c|}
\hline Station & $\begin{array}{c}\text { Distance, } \\
\text { km }\end{array}$ & $\begin{array}{l}\text { Asimuth, } \\
\text { deg }\end{array}$ & $\begin{array}{c}\text { Difference in } \\
P \text { Arrival Time, } \\
\text { ms }\end{array}$ & $\begin{array}{c}\text { Difference in } \\
P \text { Arrival Time } \\
\text { After Relocation, } \\
\text { ms }\end{array}$ & $\begin{array}{c}\text { Slope of } \\
\delta(t) \times 10^{-3} \text { and } \\
\text { Standard } \\
\text { Error of } \delta(t)\end{array}$ & $\begin{array}{l}\text { Instrument } \\
\text { Change** }\end{array}$ \\
\hline HFE & 5.5 & 79 & -1.8 & 0.1 & $0.3 \pm 0.3$ & $\ldots$ \\
\hline HCA & 6.0 & 341 & -0.8 & 0.7 & $0.9 \pm 0.3$ & VG \\
\hline HOR & 7.5 & 213 & 0.0 & 0.2 & $1.8 \pm 1.0$ & $\ldots$ \\
\hline HKR & 8.6 & 158 & 3.0 & 3.0 & $1.7 \pm 0.9$ & vs \\
\hline HFH & 9.5 & 184 & & & $1.8 \pm 0.6$ & $S$ \\
\hline HGS & 13.6 & 5 & & & $0.7 \pm 0.1$ & S \\
\hline HPH & 13.9 & 159 & 0.9 & 1.5 & $1.2 \pm 0.4$ & $\cdots$ \\
\hline HAZ & 15.2 & 229 & & & $0.7 \pm 0.3$ & $\ldots$ \\
\hline HBT & 15.8 & 210 & 0.5 & 0.5 & $0.5 \pm 0.3$ & V \\
\hline HGW & 17.5 & 286 & 0.7 & 1.0 & $0.4 \pm 0.2$ & VS \\
\hline HPL & 17.6 & 60 & -3.3 & -1.3 & $0.3 \pm 0.3$ & VF \\
\hline HSF & 18.3 & 191 & -0.3 & -0.2 & $1.1 \pm 0.3$ & $\ldots$ \\
\hline HCB & 18.3 & 255 & 1.7 & & $1.0 \pm 0.4$ & $\ldots$ \\
\hline HPR & 20.9 & 264 & -1.4 & -1.4 & $0.7 \pm 0.3$ & $\ldots$ \\
\hline HJG & 21.9 & 207 & & & $0.8 \pm 0.2$ & VFT \\
\hline HDL & 22.4 & 227 & -0.6 & -0.8 & $0.1 \pm 0.1$ & $\ldots$ \\
\hline HJS & 22.7 & 140 & -1.3 & -0.4 & $0.4 \pm 0.1$ & VS \\
\hline HFP & 24.6 & 186 & -0.8 & -0.7 & $0.2 \pm 0.2$ & $\ldots$ \\
\hline JRR & 25.2 & 291 & -0.4 & -0.1 & $0.4 \pm 0.2$ & V \\
\hline BVY & 25.3 & 170 & 0.2 & & $0.3 \pm 0.2$ & VT \\
\hline $\mathrm{JCB}$ & 25.4 & 307 & -1.2 & -0.6 & $0.5 \pm 0.1$ & $\mathrm{~V}$ \\
\hline CAD & 25.5 & 325 & -1.8 & -0.9 & $0.0 \pm 0.4$ & $\mathbf{S}$ \\
\hline BSB & 30.5 & 149 & & & $0.6 \pm 0.2$ & $\mathrm{~T}$ \\
\hline $\mathrm{HCZ}$ & 31.0 & 257 & & & $0.0 \pm 0.2$ & VG \\
\hline BCG & 31.2 & 160 & & & $0.6 \pm 0.3$ & $T$ \\
\hline BSR & 34.5 & 188 & & & $0.0 \pm 0.1$ & VT \\
\hline BNC & 36.2 & 166 & -0.7 & & $0.0 \pm 0.1$ & $T$ \\
\hline JHL & 36.3 & 294 & 2.0 & 2.3 & $0.6 \pm 0.2$ & $\ldots$ \\
\hline $\mathrm{CCO}$ & 36.7 & 329 & -0.8 & 0.2 & $0.4 \pm 0.4$ & $\ldots$ \\
\hline BLR & 38.1 & 156 & & & $0.3 \pm 0.2$ & $T$ \\
\hline JST & 39.5 & 311 & 0.0 & 0.6 & $0.0 \pm 0.2$ & V \\
\hline JAL & 39.9 & 301 & & & $0.0 \pm 0.2$ & VS \\
\hline CAO & 42.1 & 351 & & & $0.1+0.1$ & VS \\
\hline BEH & 42.8 & 143 & & & $0.6 \pm 0.2$ & $\ldots$ \\
\hline $\operatorname{CSC}$ & 44.2 & 321 & & & $0.0 \pm 0.1$ & VG \\
\hline BEN & 47.6 & 137 & & & $0.2 \pm 0.1$ & $\cdots$ \\
\hline BJC & 47.8 & 173 & & & $0.0 \pm 0.1$ & V \\
\hline BVL & 50.5 & 151 & & & $0.3 \pm 0.2$ & $\ldots$ \\
\hline
\end{tabular}

*V, VCO field unit; S, seismometer; F, FM carrier frequency; G, system gain; T, tape recorder channel assignment; and center dots indicate no change. 
indicates that time variations caused by this possibility must be small, not more than $2 \mathrm{~ms}$ on the average. We remark that errors like telephone line delays would certainly be constant along each seismogram and would not affect the relative timing measurements within the coda.

\section{Results}

Signals at 24 seismic stations have been used in this study. In the analysis, each window is shifted by $0.2 \mathrm{~s}$ relatively to the preceding one, and the coherence and phase are computed for each window (Figure 5). The coherence is close to 0.99 at the beginning of the $P$ wave train and larger than 0.95 in the coda.

A plot of the time delay $\delta(t)$ as a function of running time along the seismogram is presented in Figure 6.

From the delay time plots we measure first the absolute time difference between $\boldsymbol{P}$ waves and determine the relative location of both earthquakes. Then, we use the variation in the delay as a function of the running time along the seismogram to recover information on shear waves.

\section{$P$ Wave Delays and Relocation}

The $P$ wave delays are computed with a window beginning at the $P$ wave onset. These $P$ delays listed in Table 1 have been corrected for tape-speed error and digitization-skew error. A positive number means that the travel time was longer in 1980 than in 1978 or that the velocity was slower.

The $P$ wave delays are the differences of $P$ wave arrival times minus the difference of origin times of the two events (i.e., 15 months +12 days +23 hours $+43 \mathrm{~min}+17.54 \mathrm{~s}$ ). $\mathrm{A}$ 1.28-s window includes not only the first $P$ onset but also scattered $P$ energy. We check the stability of the delay measurement by moving the window within the $P$ wave train. $P$ delays are plotted on Figure $7 a$ as a function of the azimuth of the station relative to the earthquakes. If the two earthquakes were located at exactly the same place and if there were no change of crustal properties, the $P$ delays would all be the same. Thus the variation of the delay from one station to another represents either a slightly different hypocenter for the two events, a small change in $\boldsymbol{P}$ velocity, or both. Coherent variations in delay between groups of stations transmitted on the same telephone line are not observed and thus must be significantly smaller than the observed scatter. We have estimated the relative location of the two events using the $P$ delays, assuming a homogeneous yelocity of $6 \mathrm{~km} / \mathrm{s}$ in the source region around the doublet. The relative location $(4 \mathrm{~m}$ south, $5 \mathrm{~m}$ west, $5 \mathrm{~m}$ deep) is not this accurate, but it puts an upper bound on the distance between the two events (of the order of $10 \mathrm{~m}$ ). The residuals of the delays after relocation are listed in Table 1 and plotted in Figure $7 b$.

Changes in the $P$ velocity between 1978 and 1980 should be more evident in the residuals of the delays than in the original delays themselves. A perfect doublet would provide two kinds of information on temporal velocity changes: (1) global $P$ anisotropic change in the source region and (2) localized $P$ isotropic change in the vicinity of one individual station.

It should be noted that the technique cannot provide information on an isotropic velocity change in the source region (with radial symmetry about the doublet), as such a change would be mistaken for a difference in origin times between both earthquakes.

As a change in stress induces a change in the velocity anisotropy of rock, Nur [1971] has proposed to monitor the change in the stress field near a fault by monitoring velocity anisotropy around fault. A sin ( $2 x$ azimuth) variation would

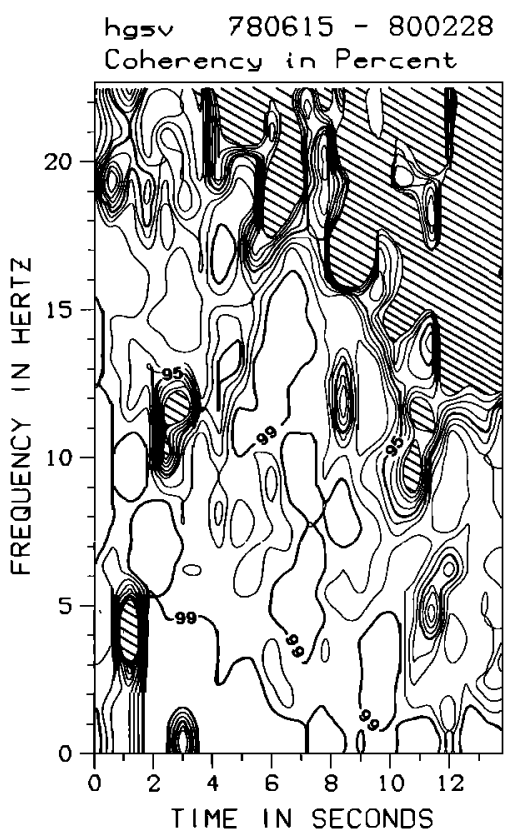

Fig. $5 a$

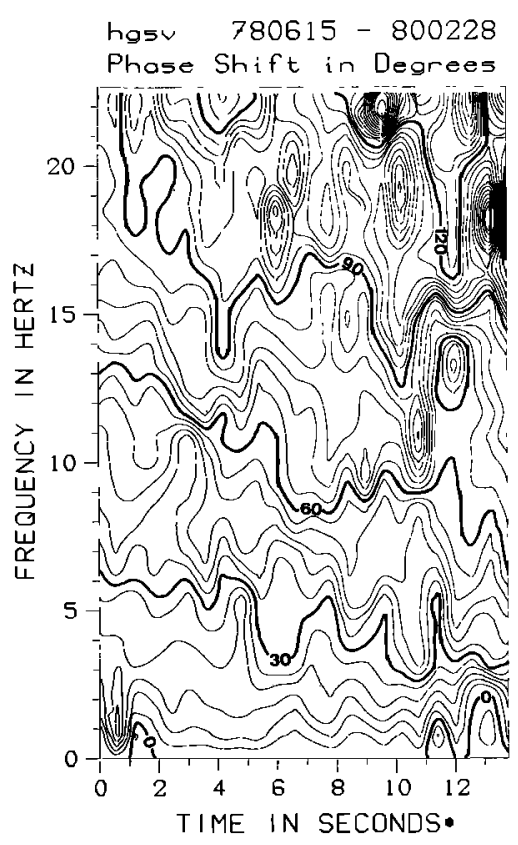

Fig. $5 b$

Fig. 5. (a) Coherence and (b) phase of the cross spectrum between the two seismograms of doublet 780615-800228 recorded in station HGSV as a function of running time along the seismograms and of frequency. Regions with coherence under $91 \%$ are hatched in Figure $5 a$. Figure $5 b$ has not been corrected for time drift.

be expected to occur near a shear fault. In theory a perfect doublet would be the seismological tool to test Nur's [1971] hypothesis and a stress change at depth should be reflected in the diagram giving the $P$ times delays as a function of azimuth. If any $P$ velocity anisotropy in the crust changed between 1978 and 1980 , it is too small to be detected by our data: it is smaller than $1 \mathrm{~ms}$. Imperfect doublets may also produce a $\sin (2 x$ azimuth) residual pattern under certain conditions, such as a fault that juxtaposes material with different $P$ velocities. 

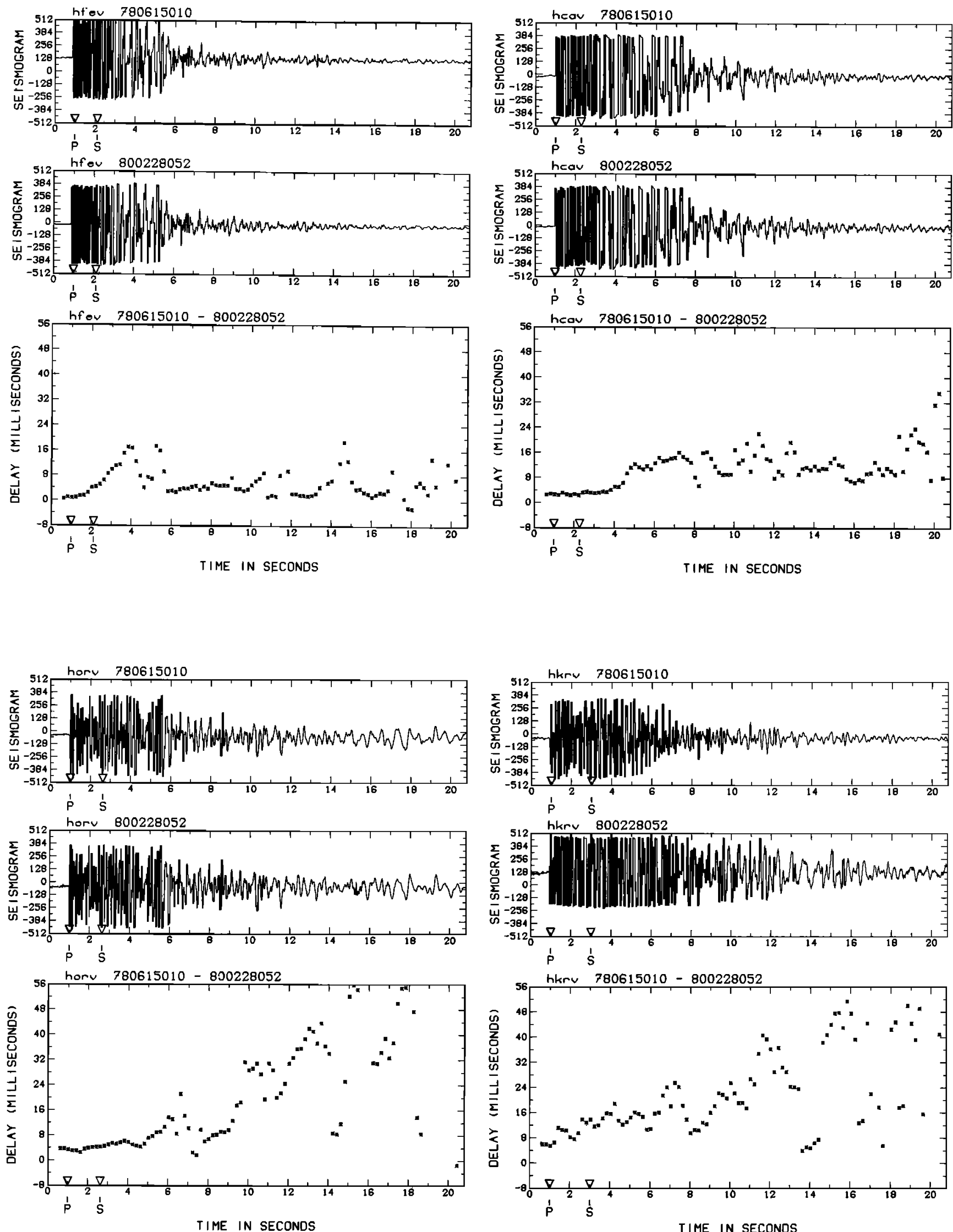

Fig. 6. Delay $\delta(t)$ of arrival times between doublet 780615 and 800228 , in milliseconds as a function of the time along the seismogram in seconds. The time base drift has been subtracted. Observed $P$ and computed $S$ arrival times are plotted. Each delay is plotted at the position of the middle of the corresponding window. The window width is $1.28 \mathrm{~s}$. 

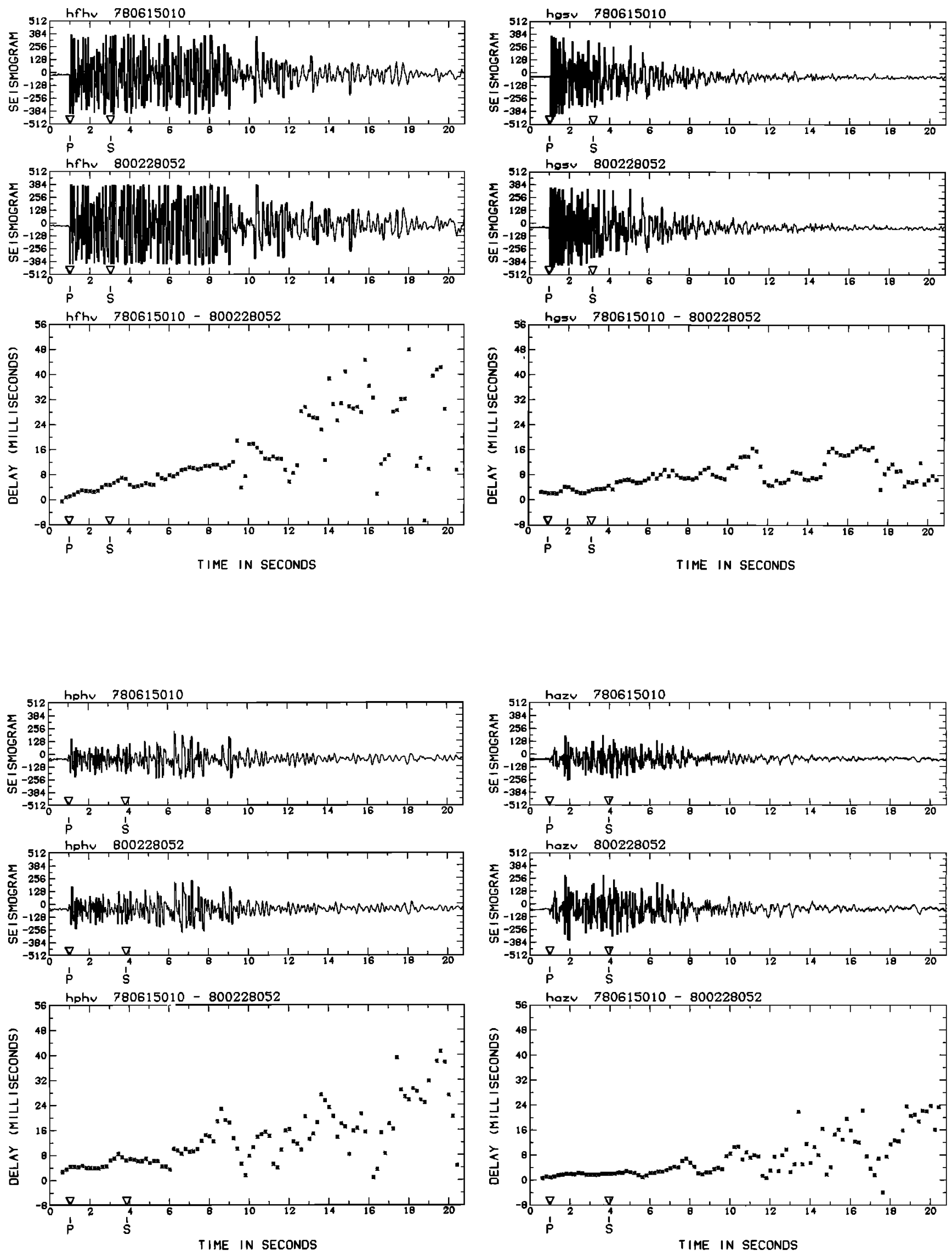

Fig. 6. (continued) 

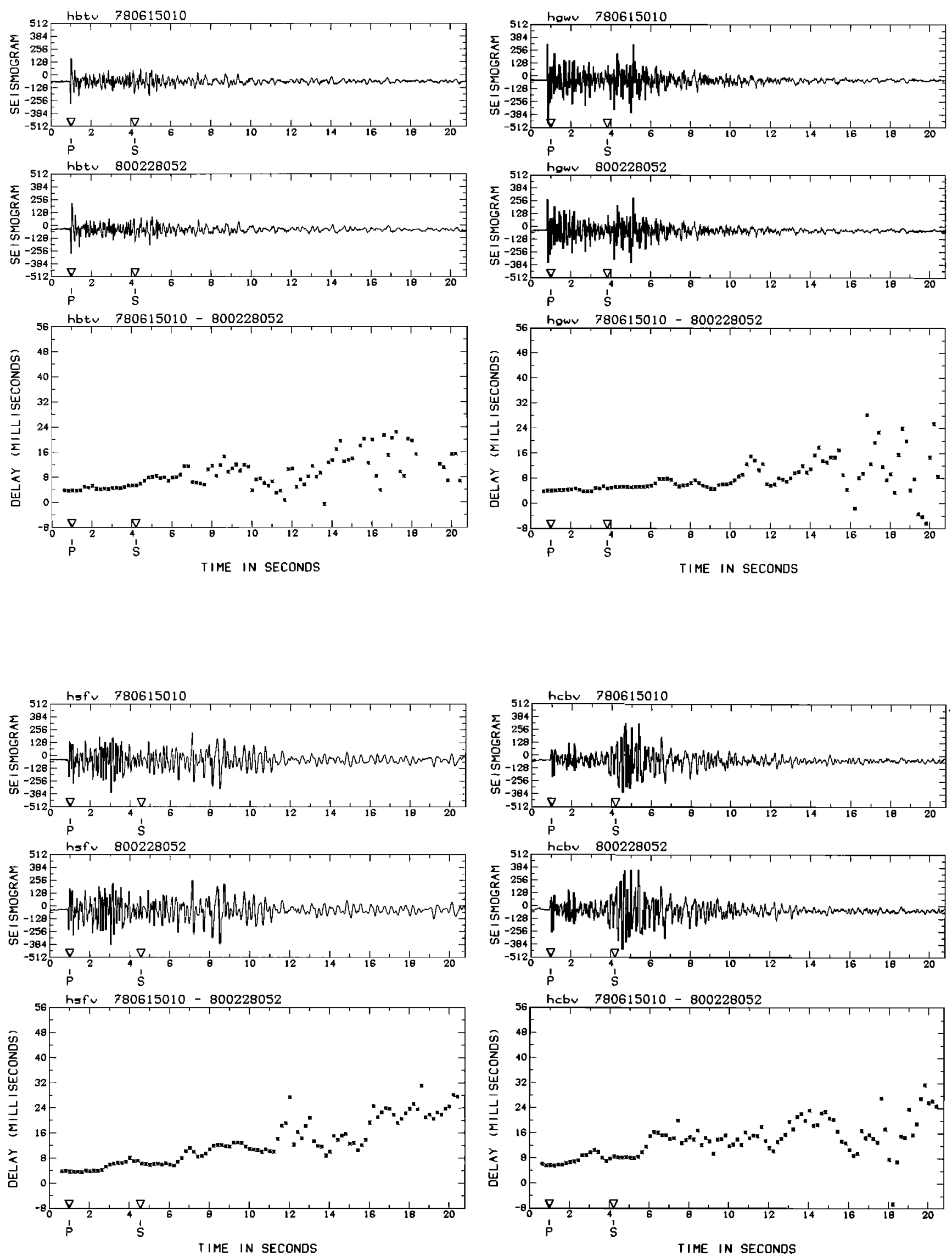

Fig. 6. (continued) 

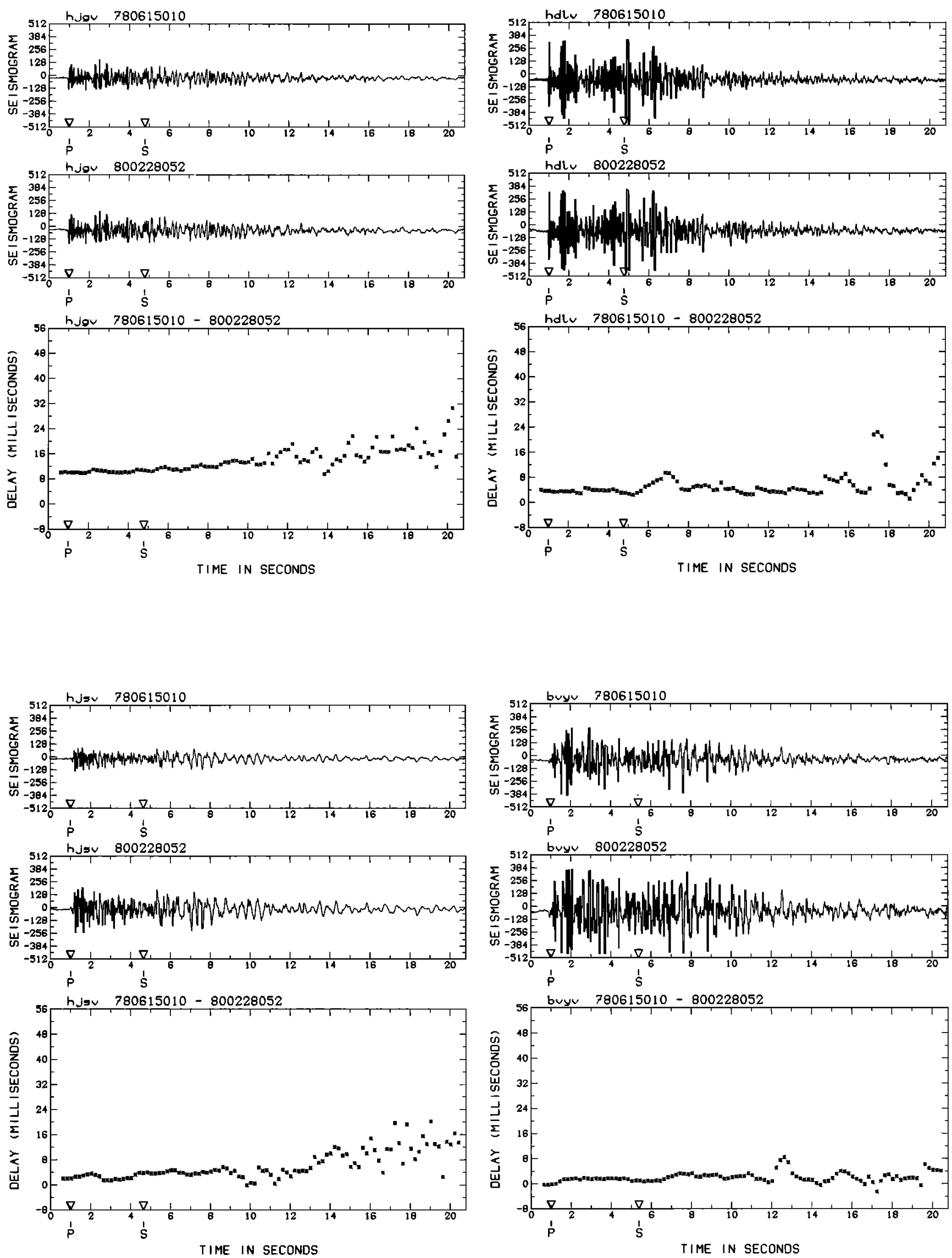

Fig. 6. (continued) 

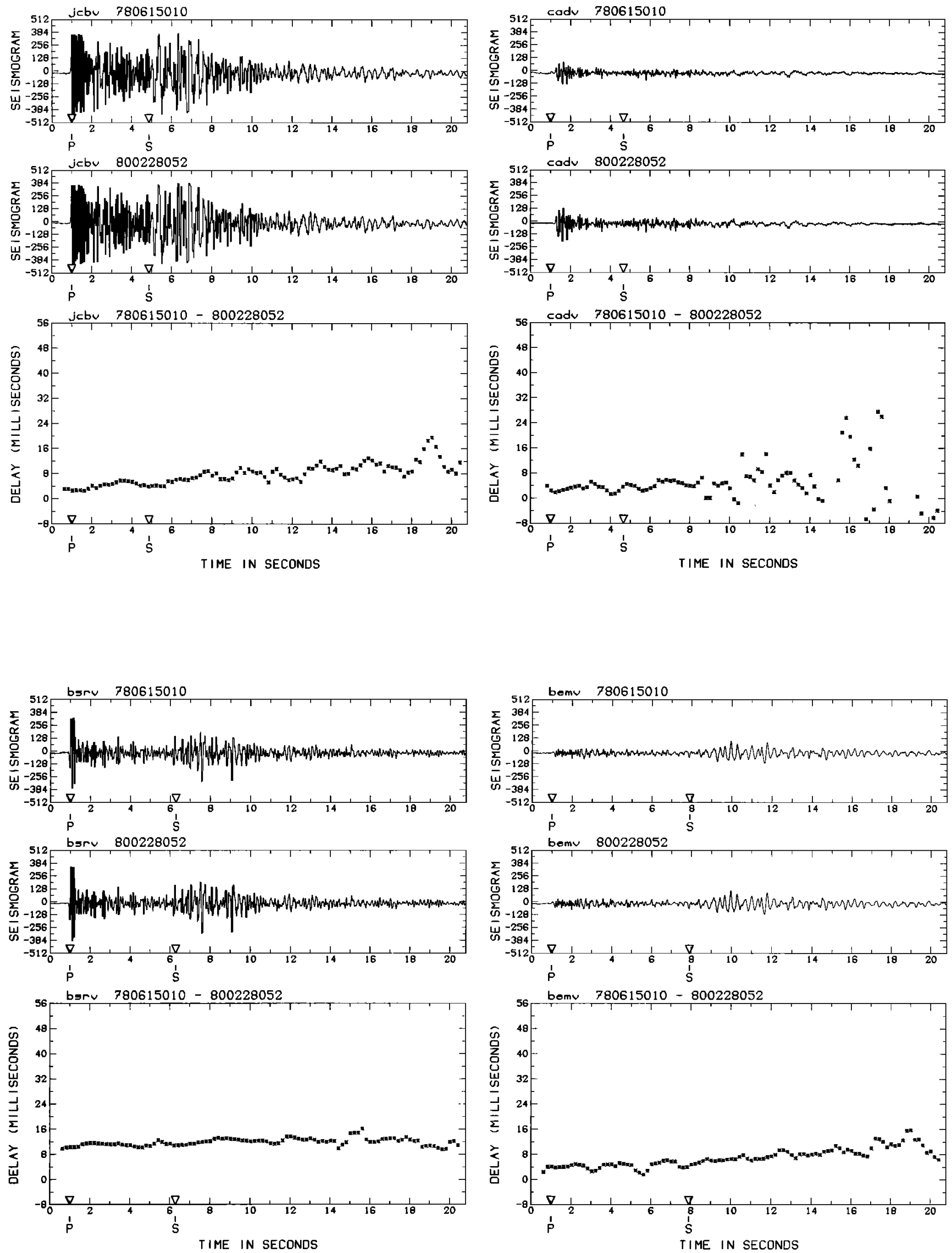

Fig. 6. (continued) 

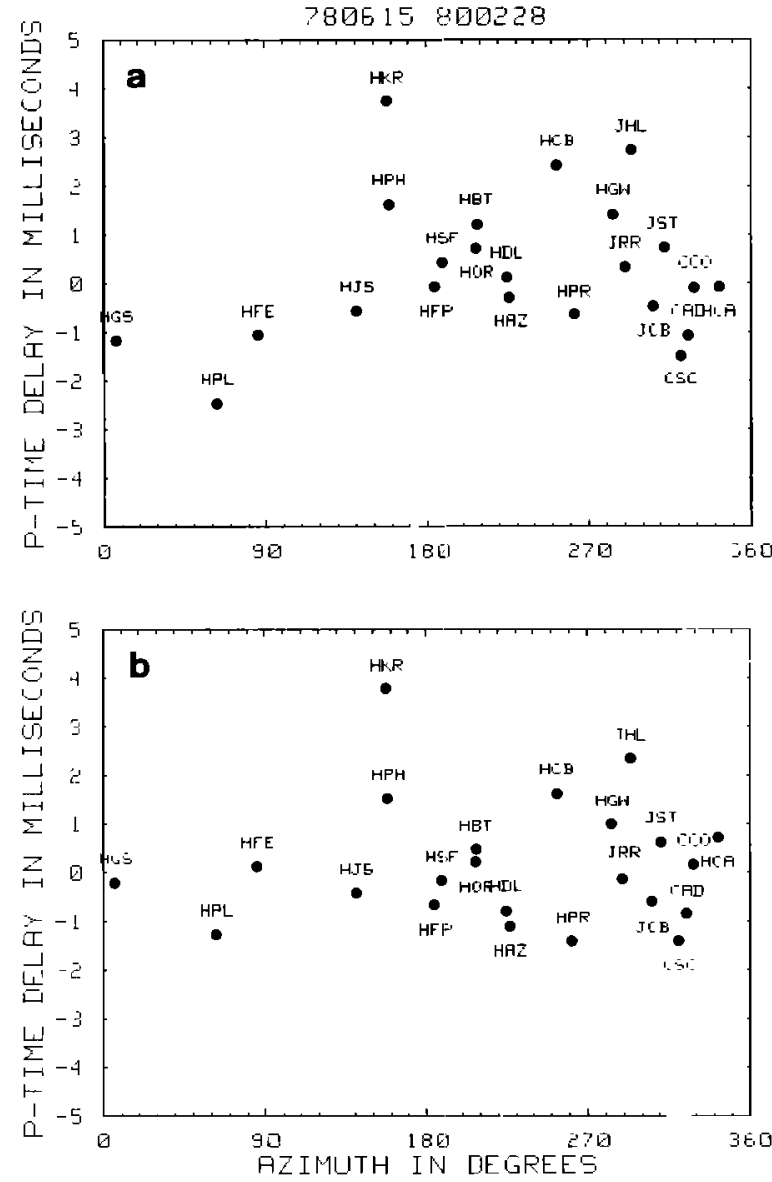

Fig. 7. $P$ wave arrival time difference between the two earthquakes in milliseconds, as a function of azimuth. (a) Residuals assuming common hypocenter. (b) Residuals after relocation.

A localized velocity change in the vicinity of one station can also be measured in this analysis even if it is a isotropic velocity change. Station HKR is the most anomalous in Table 1 and seems to be slow by $3 \mathrm{~ms}$ in 1980 compared to 1978 .

\section{$S$ Wave and Coda Delays}

The $S$ wave and coda delays exhibit a very clear change (Figure 6). For many stations, the delay increases along the seismogram. The change is so large at station HOR (Figure 6) ( $0.06 \mathrm{~s}$ after $20 \mathrm{~s}$ of signal) that it can be clearly seen in the seismograms themselves. The seismogram of the 800228 event at HOR is stretched by about $0.2 \%$ relatively to the 780615 event. As developed hereafter, we suggest that this stretching is related to a change in $S$ wave velocity.

The first part of the seismogram, the $P$ coda, is essentially $P$ and $P$ to $S$ converted phases. The later part of the seismogram, the coda, is a superposition of $S$ body waves scattered by velocity heterogeneities randomly distributed in the crust [Aki and Chouet, 1975; Chouet, 1979] and surface waves. The similarity of the seismograms for two different earthquakes means that the same scatterers or the same discontinuities are diffusing or reflecting energy in 1978 and 1980. However, when comparing nearby stations, the morphology of seismograms is sometimes very different (compare HBT and HSF), and this may point toward the fact that the coda is very sensitive to near-station heterogeneities.

Let us consider that the $S$ velocity changed in the crust in a volume between the source and receiver during the time inter- val between the two events of the doublet. Waves traveling in this volume will be delayed in proportion to their total travel time in the volume. If the entire volume between source and station traversed by the scattered waves in the coda is modified, the velocity change $\Delta V s / V s$ is given by the slope of $\delta(t)$ :

$$
d \delta / d t=-\Delta V s / V s
$$

The measurement of velocity changes does not depend on the absolute timing of seismograms, but the time base has to remain constant for the two seismograms, which we have insured by applying the delay computed from the time codes, as explained before.

In practice, we compute $\Delta V s / V s$ by fitting a line to $\delta(t)$, from the origin time onward. Values of $\Delta V s / V s$ are listed in Table 1, expressed in parts per thousand. The errors are of the order of 0.3 part per thousand and an estimate of these errors is listed. $\Delta V s / V s$ range from 0.0000 to 0.0018 . Positive values mean that phases are late in 1980 compared to 1978 . We interpret this as a $S$ velocity decrease in 1980 compared to 1978.

\section{Discussion}

In map view (Figure 8) the pattern of $S$ velocity changes exhibits a surprising degree of regularity and symmetry about the doublet's epicenter, with stations to the northeast and southeast having larger changes than those to the southwest. Changes approaching $0.2 \%$ are observed in a limited area south of the doublet. The pattern is also broadly correlated with the location of the $M 5.9$ Coyote Lake earthquake, although the peak value of the change is clearly centered to the south of the aftershock zone. Note that while station CAD and the doublet's epicenter bracket the earthquake, no velocity change is observed. Given these observations of a significant change in coda wave arrival times, which we interpret as a $S$ velocity change, let us examine its possible explanations.

We believe that all of the evidence that we have compiled supports the conclusion that we are observing a geophysical effect and not an artifact produced by the data collection, transmission, recording, and playback system. Similarly, the effects are large enough that they can be directly observed in the seismograms and thus are not an artifact of our analysis procedures. Among the suite of physical explanations for the change, we consider here but two that might be responsible for the observations: a tectonic stress change and a change in the water table. We feel that either mechanism could conceivably produce localized velocity variations of the order that are observed but that a tectonic change represents the most likely explanation for the regional change. However, since the propagation mode and average depth of propagation of the coda waves is not known in detail, an unambiguous identification of the mechanism(s) cannot be made at this time.

Release of tectonic stress in the Coyote Lake earthquake is one possible tectonic mechanism that could produce a $S$ velocity change of the order of $0.1 \%$. Moos and Zoback [1984] have reported laboratory and in situ values for $\left(d V_{s} / V_{s}\right) / d P$ of $5-10 \times 10^{-4} /$ bar at depths above $5 \mathrm{~km}$. The regional stress change produced by the Coyote Lake earthquake and its afterslip, though not known in detail, is of the order of magnitude of 1 bar. For example, if the stress drop of the earthquake were uniformly distributed on a $20-\mathrm{km}$-long by $10-\mathrm{km}$ deep surface, the stress drop would be 1.8 bars. Furthermore, postearthquake measurement of geodetic displacements in the region [King et al., 1981] showed that sympathetic displace- 


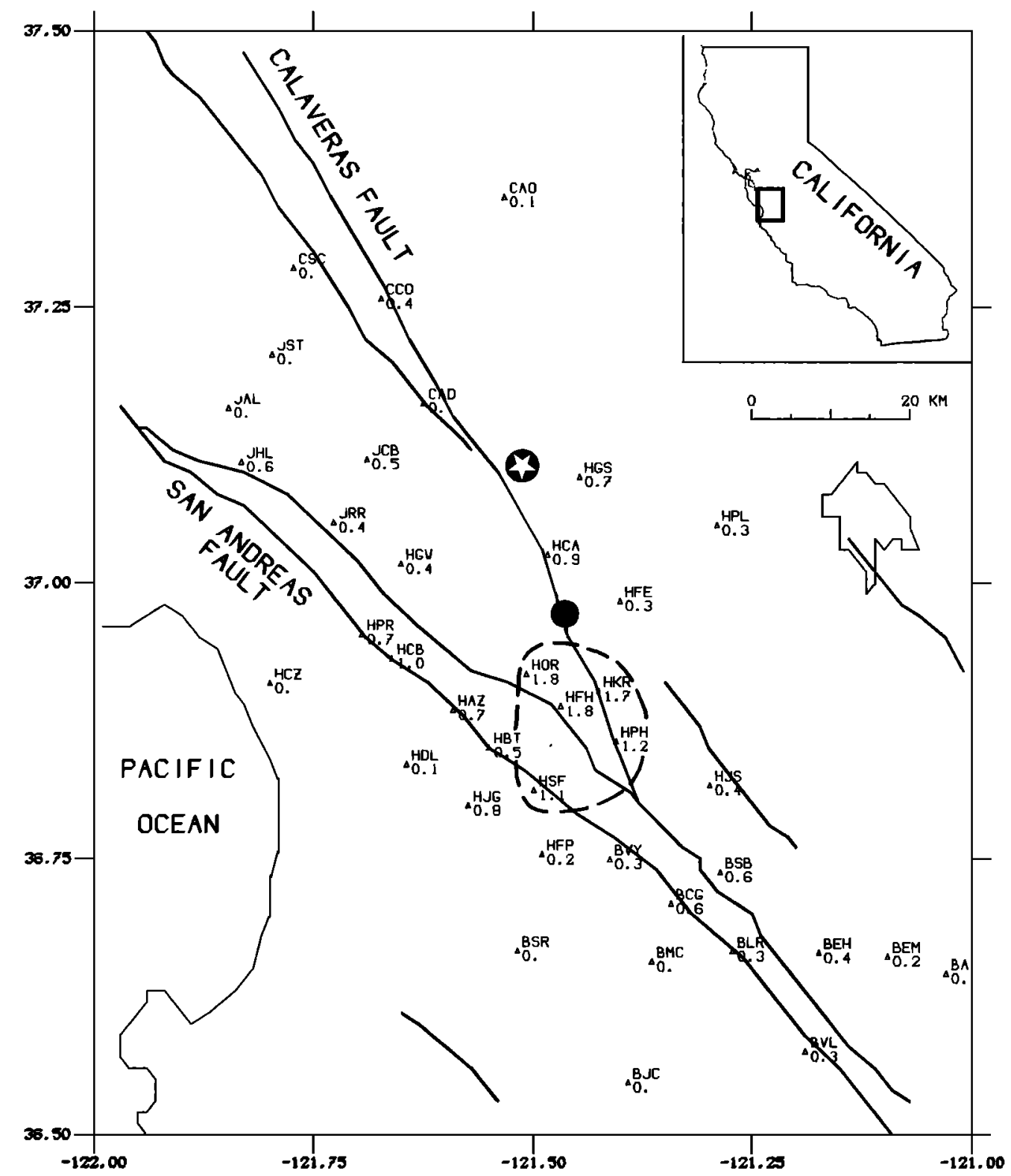

Fig. 8. Map of the slope of $\delta(t)$ observed for doublet 780615 and 800228 . These numbers are assumed to represent the average change of $S$ velocity (i.e., $\Delta V s / V s$ in parts per thousand), assuming that the entire volume between source and receiver was modified. The dashed contour outlines the anomalous zone with change larger than 0.001 .

ments of 3-4 cm occurred across the Calaveras fault well to the south of the aftershock zone (at least as far as station HPH). Thus, coseismic and postseismic effects of the earthquake extended through the region of maximum velocity change.

While this interpretation is plausible, we must be cautious about embracing it, for other possibilities cannot be ruled out at present. In particular, ground water effects may be important, as the region of maximum change is also a heavily irrigated valley. The annual drawdown of the water table exceeds $10 \mathrm{~m}$ at some locations, while at other locations, longer-term variations of the same order that are related to climatic variations in rainfall are observed [see Schulz et al., 1983, Figure 14]. Such dramatic changes in the water table could be the cause of the $P$ wave travel time change at HKR and could offer an alternative model to the tectonic stress change hy- pothesis developed above to explain the changes in coda wave travel times.

Clymer and McEvilly [1981] reported seasonal first $P$ wave arrival time changes of up to $20 \mathrm{~ms}$ measured over short distances at a site near our station BVY. The travel times they measured were longer during the rainy season (NovemberApril) and shorter in the dry season. They concluded that the seasonal variations were due to near-surface saturation changes, although water levels in a nearby well were also correlated with their observations.

If we hypothesize that the observed changes in coda wave travel times for our doublet are related to seasonal variations in ground saturation or in the water table, then we must conclude that the coda waves repeatedly sample the near surface as they propagate, otherwise they would not exhibit progressively increasing time delays. Systematic changes in the 
water table not withstanding, we do find it remarkable that the region with a velocity change of $0.05 \%$ covers both mountainous regions as well as sedimentary troughs.

\section{Conclusion}

We have presented a technique that improves the precision in measuring temporal variations of the velocity of body waves using data from microearthquake networks. In the $\delta(t)$ doublet technique, the time delay $\delta(t)$ is plotted as a function of the running time along the seismogram, and we compute the fractional change in $S$ velocity from the slope of $\delta(t)$. This technique is applied to a doublet that spans in time the Coyote Lake earthquake and is located on the segment of the Calaveras fault that ruptured during the main shock. No $P$ velocity anisotropy change is observable between 1978 and 1980 within the error limits of $1 \mathrm{~ms}$. A change of $S$ velocity, $\Delta V s / V s=0.002$ is detected in a small region near the southern tip of the rupture zone. This may reflect a decrease in stress or a change in crustal properties in that region following or more likely associated with the Coyote Lake earthquake or seasonal variations in groundwater conditions.

This technique can easily be applied to data from other seismographic networks, provided that the time base is sufficiently stable. A change of the order of $0.1 \%$ in $S$ velocity should be detectable on most single seismographic stations. An accurate digital recording system could monitor changes in $P$ and $S$ velocity of the ordet of $0.01 \%$.

Acknowledgments. We (G.P. and J.F.) thank the staff of the U.S. Geological Survey, Office of Earthquakes, Volcanoes and Engineering, Menlo Park, particularly, P. Reasenberg and L. Shijo, for their help in collecting and digitizing the data. We are grateful to $M$. J. Fremont for her help in processing the data. The original manuscript was much improved with suggestions from Bill Bakun, Gary Fuis, and Bruce Julian and anonymous journal reviewers. The funding for this work was provided by the French Institute of Astronomy and Geophysics (INAG), ATP Sismogenese, and by the U.S. Geological Survey.

\section{REFERENCES}

Aki, K., and B. Chouet, Origin of coda waves: Source, attenuation and scattering, J. Geophys. Res., 80, 3322-3342, 1975.

Boore, D. M., A. G. Lindh, T. V. McEvilly, and W. W. Tolmachoff, A search for travel time changes associated with the Parkfield earthquake of 1966, Bull. Seismol. Soc. Am., 65, 1407-1418, 1975.

Buchbinder, G. G. R., and C. M. Keith, Stability of $P$ travel times in the region of la Malbaie, Quebec, Bull. Seismol. Soc. Am., 69, 463$481,1979$.

Chouet, B., Temporal variation in the attenuation of earthquake coda near Stone Canyon, Geophys. Res. Lett., 6, 143-146, 1979.

Clymer, R. W., and T. V. McEvilly, Travel-time monitoring with Vibroseis, Bull. Seismol. Soc. Am., 7I, 1903-1927, 1981.

Eaton, J. P., Frequency response of the USGS short period telemetered seismic system and its suitability network studies of local earthquake, U.S. Geol. Surv. Open File Rep., 77-844, 45 pp., 1977.

Ellis, J. R., and A. Lindh, Linearity of VCO-discriminator playback system with respect to zero crossing times, U.S. Geol. Surv. Open File Rep., 76-873, 8 pp., 1976.

Geller, R. J., and C. S. Mueller, Four similar earthquakes in central California, Geophys. Res. Lett., 7, 821-824, 1980.
Glangeaud, F., Signal processing for magnetic pulsation, J. Atmos. Terr. Phys., 43, 981-998, 1981.

Healy, J. H., and M. E. O'Neill, Calibration of seismographic systems: USGS stations in the central California network, U.S. Geol. Surv. Open File Rep., 77-736, 178 pp., 1977.

Kanamori, H., and G. Fuis, Variation of $P$-wave velocity before and after the Galway Lake earthquake $\left(M_{L}=5.2\right)$ and the Goat Mountain earthquake $\left(M_{L}=4.7\right)$ in the Mojave Desert, Bull. Seismol. Soc. Am., 66, 2017-2037, 1976.

King, N. E., J. C. Savage, M. Lisowski, and W. H. Prescott, Preseismic and coseismic deformation associated with the Coyote Lake, California, earthquake, J. Geophys. Res., 86, 892-898, 1981.

Leary, P. C., and P. E. Malin, Millisecond accurate monitoring of seismic travel times over 13- and 18-kilometer baselines, J. Geophys. Res., 87, 6919-6930, 1982.

Leary, P. C., P. E. Malin, R. A. Phinney, T. Brocher, and R. VonColln, Systematic monitoring of millisecond travel time variations near Palmdale, California, J. Geophys. Res., 84, 659-666, 1979.

Lee, W. H. K., D. G. Herd, v. Cagnetti, W. H. Bakun, and A. Rapport, A preliminary study of the Coyote Lake earthquake of August 6, 1979 and its major aftershocks, U.S. Geol. Surv. Open File Rep., 79-1621, 43 pp., 1979.

Lukk, A. A., and I. L. Nersesov, Character of temporal changes in the velocities of elastic waves in the earth's crust of the Garm region, Izv. Acad. Sci. USSR Phys. Solid Earth, 14, 387-396, 1978.

Moos, D., and M. D. Zoback, Comparison of in situ and laboratory determined pressure dependence of $P$ - and $S$-velocities, Bull. Seismol. Soc. Am., in press, 1984.

Nakamura, Y., $A_{1}$ moonquakes: Source distribution and mechanism, Proc. Human Planet. Sci. Conf., 9th, 3589-3607, 1978.

Nur, A., Effect of stress on velocity anisotropy in rocks with cracks, $J$. Geophys. Res., 76, 2022-2034, 1971.

Nur, A., Dilatancy, pore fluids and premonitory variations of $t s / t p$ travel times, Bull. Seismol. Soc. Am., 62, 1217-1222, 1972.

Poupinet, G., F. Glangeaud, and P. Cote, $P$-time delay measurement of a doublet of microearthquakes, Proc. IEEE, ICASSP82, 15161519,1982

Reasenberg, P., and K. Aki, A precise continuous measurement of seismic velocity for monitoring in situ stress, J. Geophys. Res., 79, 399-406, 1974

Reasenberg, P., and W. L. Ellsworth, Aftershocks of the Coyote Lake, California earthquake of August 6, 1979: A detailed study, J. Geophys. Res., 87, 10637-10655, 1982.

Rikitake, T., Earthquake Prediction, 357 pp., Elsevier, Amsterdam, 1976.

Schulz, S., R. O. Burford, and B. Mavko, Influence of seismicity and rainfall on episodic creep on the San Andreas fault system in central California, J. Geophys. Res., 88, 7475-7484, 1983.

Semenov, A. M., Variations in the travel time of transverse and longitudinal waves before violent earthquakes, Izv. Acad. Sci. USSR Phys. Solid Earth, no. 4, 245-248, 1969.

Uhrhammer, R. A., Observations of the Coyote Lake, California earthquake sequence of August 6, 1979, Bull. Seismol. Soc. Am., 70, 559-570, 1980

Wesson, R. L., R. Robinson, C. G. Bufe, W. L. Ellsworth, J. H. Pfluke, J. A. Steppe, and L. C. Seekins, Search for seismic forerunners to earthquakes in Central California, Tectonophysics, 42, 1111-1126, 1977.

W. L. Ellsworth, U.S. Geological Survey, 345 Middlefield Road, MS/977, Menlo Park, CA 94025.

J. Frechet and G. Poupinet, IRIGM, Universite Scientifique et Medicale de Grenoble, BP 68, F38402, St. Martin d'Heres, France.

(Received March 14, 1983; revised March 8, 1984; accepted March 19, 1984.) 